\title{
Secrets and silence: agency of young women managing HIV disclosure
}

Constance RS. Mackworth-Young ${ }^{1,2 \S}$, Virginia Bond ${ }^{1,2}$, Alison Wringe ${ }^{3}$

1. Department of Global Health and Development, Faculty of Public Health and Policy, London School of Hygiene and Tropical Medicine, 15-17 Tavistock Place, London, WC1H 9SH, United Kingdom

2. Zambart, School of Public Health, Ridgeway Campus, University of Zambia, Lusaka, 10101, Zambia

3. Department of Population Health, Faculty of Epidemiology and Population Health, London School of Hygiene and Tropical Medicine, Keppel Street, London, WC1E 7HT, United Kingdom

${ }^{\S}$ Corresponding Author: Constance RS. Mackworth-Young

London School of Hygiene and Tropical Medicine,

15-17 Tavistock Place, London, WC1H 9SH, United Kingdom

Phone: +447522426891

Email: constance.mackworth-young1@1shtm.ac.uk 


\section{Secrets and silence: agency of young women managing HIV disclosure}

Drawing on a 12-month ethnography with young women living with HIV in Zambia, we explore their everyday strategies to avoid unintentional disclosure of their HIV status. Young women practiced secrecy with sexual partners, through hiding their antiretroviral therapy and using veiled language around HIV. Whilst remaining silent about their HIV status enabled them to maintain identities beyond HIV, this secrecy triggered feelings of guilt and anxiety, suggesting that their agency was "bounded" (Evans 2007) by the context of persistent stigma. These strategies to hide their HIV status question public health narratives urging disclosure, and support disclosure-counselling approaches that champions choice.

Media teaser: Young Zambian women living with HIV enact "bounded agency" through social practices of secrecy and silence to avoid unintentional disclosure of HIV, and protect their identities. 
Young women living with HIV in sub-Saharan Africa often experience persistent stigma, commonly leading to limited disclosure networks (Mburu, et al. 2014). Though encouraged by counsellors, the process of disclosing HIV status can provoke anxiety and has the potential to have either a positive or negative impact, including on individuals' identities and relationships (Toska, et al. 2015). Much research with young people living with HIV has highlighted the challenges, such as stigma, that they face when considering disclosure, but often does little to extend our understanding of the factors and choices that young people make to moderate or mediate these negative impacts of HIV (Skovdal and Daniel 2012; Theron and Theron 2010). Since youth is a period of social change, relationship formation and identity development (World Health Organization 2017), the negative social impact of HIV disclosure can have especially strong effects on young people, and strategies for coping often take on a social form (Skovdal and Ogutu 2013).

Young people affected by HIV have demonstrated individual strategies of tapping into their inherent strengths to become agents in care and support (Khanare 2012). If young people living with HIV seek social support, this has been shown to reduce anxiety and depression (Seffren, et al. 2018), support adherence (Denison, et al. 2015), and enable progression through the HIV continuum of care (MacPherson, et al. 2012). Disclosure to others is best understood as a process, which often includes targeting who to tell based on relationship quality and minimising risks of rejection, rehearsing how to disclose, and 'testing the waters' through incremental clues (Cusick and Rhodes 1999). In a study in the US, young people living with HIV described strategies to manage the impact of the disclosure process on their identities, including getting to know a new sexual partner before disclosing to them in order to postpone and lessen the negative 
impact of disclosure (Frye, et al. 2009). However, we have limited understanding about the everyday strategies that young women living with HIV undertake to mediate the potential challenges of unintentional HIV disclosure.

\section{Disclosure and secrecy}

One strategy to avoid the challenges associated with HIV disclosure in certain contexts is secrecy. The majority of young women living with HIV have limited disclosure networks, and are careful over who they choose to tell about their HIV status (Fielden, et al. 2011; Mburu, et al. 2014). In a study in Uganda and Kenya, over half of adolescents living with HIV had never told anyone their HIV status (Nostlinger, et al. 2015). Family members or caregivers of young women living with HIV often strongly discourage disclosure, to protect not only the adolescent, but also themselves or their families from anticipated stigma and potential discrimination, especially in cases of mother-to-child transmission (Mackworth-Young, et al. 2017).

However, the value of secrecy as a strategy to navigate the potentially negative consequences of stigma is challenged in a context where the personal and public healing effects of disclosure are emphasised (Nguyen 2013:440). Numerous accounts describe the liberating effect of disclosure (e.g. Paxton 2002). This is linked to empowerment speak of "coming out" and discourses of therapeutic citizenship, where people living with HIV can demand and access antiretroviral therapy (ART) only once they have "confessed" (Nguyen 2010:1,35). Disclosure is therefore encouraged, not just for individual liberation and prevention of the onward transmission of HIV, but also for wider societal mobilisation and contestation of stigma (Paxton 2002). However, as 
critiqued by Hardon and Posel, this emphasis on disclosure and the pejorative notion of secrecy risks that the "prescription to be open about these issues will become monochromatic, blunt and unduly coercive, based on a misreading of more nuanced ways of knowing and telling, ignoring the more complex psychology and anthropology of making and keeping secrets" (2012:3). We draw on Hardon and Posel's notion of secrecy as a deeply relational social practice, where what we reveal and what we withhold is shaped by agency bounded by social and structural factors (2012).

\section{"Bounded" agency}

Bourdieu theorises agency as the interactions between agents and their environment, thereby positioning choices within, and responsive to, social processes (Bourdieu 1977). Women's agency has been considered as being along a continuum, where a woman's position varies over time and between relationships (Stoebenau, et al. 2016). Popular discourses of young people and HIV are often situated within a framework of vulnerability and a lack of agency, which can overlook strategies that young people employ in their daily lives (Pincock 2017). Cognisant of the particular social and structural constraints that young people face, Evans introduced the concept of "bounded agency", which is "socially situated agency, influenced but not determined by environments" (Evans 2007, p. 17). Through "bounded agency", individuals are understood as actors within structures, with space open for action but within the constraints of the "social landscape" (Evans 2007, p. 2). Some of these constraints are difficult to move, while others can be circumnavigated, altered or resisted. We build on Evan's concept of "bounded agency" to explore how young women living with HIV 
adopt secrecy as a strategy of resistance to norms concerning HIV status disclosure in the context of a particular social landscape.

\section{Managing identity}

Employing agency through the practice of secrecy in the context of a stigmatised disease can be seen to impact one's identity. The concept of identity was explored by Goffman in his seminal work on stigma, which theorised how individuals who are unable to conform to society's standards of normality are seen to have "spoiled identities" (1963:31). Chronic or acute health conditions can be seen as a "disruption" to identity (Bury 1982:167), which then requires review, maintenance and repair (Corbin and Strauss 1987). This resonates with understandings of the ways that changes in HIV status can impact on identity, including through abrupt biographical disruption, and loss of a communal self with changes to relationships and support networks (Freeman 2017; Russell and Seeley 2010; Seeley, et al. 2012). However, we have more limited understanding of how people maintain or protect their identity throughout the course of living with HIV, including through the choices made around HIV status disclosure. Goffman's work has been criticised for centring on the stigmatised, without a focus on those who impose stigma, thus situating stigmatised individuals as victims who lack agency and overlooking how social life and relationships are altered by stigma (Kleinman and Hall-Clifford 2009). Broader understandings of stigma acknowledge the socially embedded context, which enable structural discrimination that leads to individual stigma (Kleinman and Hall-Clifford 2009; Link and Phelan 2001). We draw on and beyond Goffman's notion of stigma to explore how, in the context of a stigmatised disease, young women use their agency within cultural and structural 
contexts to practice secrecy in order to navigate disclosure within their relationships and therefore manage their wider identities.

Income level can contribute to identity formation, as well as being an important factor determining the strategies that individuals may use to manage their identities, including secrecy. Despite having high HIV prevalence in some sub-Saharan African countries, such as Zambia (Central Statistical Office and Ministry of Health 2014) and Tanzania (Long and Deane 2015), middle-income populations have been notably underresearched, with the HIV epidemic remaining firmly rooted in a poverty narrative (Fenton 2004). Middle-income populations face particular vulnerabilities, such as high sexual risk behaviours and high HIV prevalence, and are overdue focused research (Long and Deane 2015). Further, middle-income groups may have particular motivations for secrecy around HIV, including protecting particular identities, such as college students or employees, and particular strategies for doing so. This research gap, alongside practical and language considerations for data collection, underlies the purposeful selection of middle-income young women living with HIV for this ethnographic study.

In this article, we explore the intersections between agency and identity to understand the everyday strategies employed by middle-income young women living with HIV in urban Zambia to manage disclosure of their HIV status. We explore how secrecy and silence are practiced as strategies to manage their identities in the face of pervasive stigma, and the impact that this has on their lives. 


\section{Research methods and setting}

This ethnographic study aimed to understand the impact of HIV on the everyday lives of young women living with HIV. The lead researcher (initials removed for peer review) conducted twelve months of participant observation with seven young women living with HIV (aged 17-19 years) in Lusaka in 2017-2018. This study arose out of an earlier qualitative study in 2014-15 and subsequent support group intervention in 2016 with a larger cohort of young women living with HIV (Mackworth-Young, et al. 2017). Building on this earlier contact, young women from that cohort who were middleincome (defined as having a parent or guardian working in a formal job, and living in a middle-income area of Lusaka) and spoke English were purposefully selected to participate in the ethnography. Seven young women participated in the ethnography

(Table 1). They were all on HIV treatment, identified as Christian, and had completed secondary school.

Fieldwork mostly occurred in Lusaka, the capital city and largest urban centre in Zambia. This research largely took place in low-density, middle-income areas of Lusaka, where the young women lived, studied at college, shopped, met with friends, and went to church and to the clinic. In these areas the main roads are tarred and smaller roads are dirt. Most areas have a main shopping centre, a government health facility, as well as dozens of schools, informal shops, cafes, bars and churches. A walled fence usually surrounds each house or collection of houses in these areas, with a gate at the entrance, and a small yard around the house. Inside most houses in these middle-income areas, there is a kitchen, living room with sofas and a television, a bathroom with running water, and two to three bedrooms, shared by all household members. Most 
participants shared their bedrooms with cousins or other family members, and sometimes also with visitors when they stayed. The participants' bedrooms usually had one double bed (usually shared with other female family members), a tall cupboard and chest of drawers full of clothes and shoes, with bags or suitcases of clothes or other possessions in bags on top. Participants' ART was usually stored in their bedrooms, either in their bedside table, or hidden in a drawer amongst their clothes. Participants studying in college stayed in boarding houses, sharing dormitories with one to seven other young women, with shared bathrooms and limited private space.

Participant observation involved the lead researcher spending time with the seven young women across a range of settings (including home, recreational, colleges and clinics), sometimes in the company of their family, friends and boyfriends, and sometimes on their own. Between 12 and 24 blocks of time were spent with each of the young women over the twelve months. Each session of observation was arranged by phone with the participant, usually initiated by the researcher, ensuring no more than a few weeks passed between each session with each participant. Less frequently, participants initiated meeting up by suggesting the researcher join a particular activity that they were doing. Field notes were written up soon after each participant observation, capturing the detail of places, discussions, relationships with others and personal reflections.

The lead researcher mostly spent time with the young women individually as opposed to seeing them together. The exception was participatory workshops held at the beginning and end of the fieldwork period when all the young women and the lead researcher came together. The first workshop discussed the purpose of the research and 
how to introduce the research to others, and the second validated the preliminary findings with the young women. To illustrate the range of data collection methods, below is a description of the data collection with one participant, Rhoda, over the course of the 12-month ethnography. Rhoda was asked to participate and gave consent in September 2017. She participated in the introductory workshop with the other participants. The researcher had 17 sessions of participant observation with her, including at her home $(n=3)$, at her place of work $(n=3)$, in recreational spaces including cafes and shopping areas $(n=6)$, at church $(n=1)$, at the clinic, including a peer education session $(n=1)$ and at an NGO $(n=3)$. Rhoda participated in the closing workshop with the other participants in September 2018.

Additional to the ethnography with young women living with HIV, 14 young women with negative or unknown HIV status were recruited to attend a one-day participatory workshop, which aimed to compare their experiences to the young women living with HIV to understand what experiences might be specific to living with HIV, or more generally related to being a young woman. Nine young women were recruited through convenience sampling through colleagues of the authors in Lusaka, and these young women themselves recruited a further five young women through snowball sampling. The selection criteria were being aged 18-21 years, living in Lusaka, being middleincome and having a negative or unknown HIV status. In the workshop, discussions explored the role and place of secrets and disclosure of information in the context of their social relationships.

Conducting the ethnography over twelve months allowed time for findings to initiate both further enquiry and deeper analysis, developed through reflective memos and 
conversations with the research team. The theme of secrecy as a strategy to prevent unintentional disclosure emerged out of this process. This then influenced subsequent data generation, which consequently included a specific focus on this topic, including discussions around secrecy in the workshop with young women who had negative or unknown HIV status. At the closing workshop with the young women living with HIV, the participants were asked to collectively analyse the initial results on secrecy, unintentional disclosure, the strategies they used to hide their HIV status, and the impact these had on their lives. This included brainstorming in pairs about the strategies that they used to hide their HIV status, and a 'card-storm' activity, writing and discussing words they used to discuss and conceal HIV. In the workshop, participants discussed how the word "lies" was a strong word with negative connotations, but, since it was the word that they collectively chose to use to describe their experiences around HIV disclosure, we have used the term in this analysis. After the completion of data collection, data relating to this thematic area were coded manually, using the following broad codes which were developed inductively during data analysis: unintentional disclosure; stories told to hide HIV status; hiding ART; veiled language; researcher's experience of secrecy. Data were then grouped and analysed thematically. The themes that emerged form the structure of this manuscript: i) secrecy in sexual relationships; ii) secrecy around ART; iii) secrecy in language; iv) secrecy through stories; v) fear and anxiety around secrecy; and vi) secrecy beyond HIV.

Ethical clearance was obtained from the review boards of the University of Zambia Humanities Research Ethics Committee and the London School of Hygiene and Tropical Medicine, and approval was granted by the Zambian Ministry of Health. Participants were asked for their written consent to participate in the study, as well as 
their parents or guardians, due to the familial and intimate nature of the ethnographic study, which involved spending large amounts of time in participants' homes. The risk of unintentional disclosure of the young women's HIV status was discussed with participants during informed consent and in the introductory workshop. In the introductory workshop, the young women reached a consensus to describe the research to others who did not know their HIV status as anthropological research looking at the everyday lives of young women in Lusaka, thereby maintaining confidentiality about HIV status. The researcher also agreed to adapt this to the specific circumstances for each participant, if they felt that for particular individuals a different story would be more appropriate in a particular context to hide their HIV status. For example, one participant told her uncle that she had met the researcher at her workplace, and another told her friend that she met the researcher at church. Pseudonyms were used in writing participant observation notes and results. The navigation of ethical issues by the researcher in the study was explored separately through a detailed analysis reported elsewhere (Mackworth-Young., et al. 2019).

There are several limitations to the study. Firstly, the research only considered the experiences of young women, thereby not representing the views of young men who are living with HIV, which remain underrepresented in ethnographical research (eg. Simpson 2009), and are needed to understand gender differences. Secondly, I decided not stay with any of the participants in their households overnight for ethical and practical reasons, and this may have limited the extent to which I could immerse myself totally in their lives. Lastly, although I learnt basic Nyanja, and could converse with the participants and their families, not being fluent in the language meant that I missed some of the nuanced content in these conversations. However, with this group of 
middle-income young women, English was the predominant language, so, on the whole I could understand and participate fully in their social interactions. 


\section{Silence in sexual relationships: "I won't tell him about my status"}

All the young women were in relationships at some point during the study, mostly longterm steady boyfriends, but also, less commonly, short-term sexual relationships, which were occasionally concurrent. For the young women, their boyfriends were central and exciting parts of their lives. However, their HIV status was a consistent worry to them in their relationships. They worried about whether, how and when to disclose their HIV status, what reaction they would receive, and how to protect themselves and their boyfriends if and when they had sex. Most participants did not disclose their HIV status until their relationship "became serious" (Thandi, participant observation), which to Thandi meant being a close and exclusive couple, but not yet sexually active. However, they continuously feared that their boyfriends would find out about their HIV status. Even when participants made a conscious decision to disclose their status to their boyfriends, the continued fear of potential negative consequences plagued their thoughts. After Mary had told her boyfriend that she was living with HIV, even though he had reacted well, she said:

You know, I think hard about things, and I really wonder whether I will ever get married in my state. Maybe he'll accept it for a while, but one day, he might just think differently about it, and realise that he doesn't want to be with me because of that thing. And then it makes me think whether anyone would want to marry me. It's something I think about a lot. (Mary, participant observation).

Unintentional disclosure of their HIV status was described as "the worst thing that could happen to me" (Mary, participant observation), with the fear and the potential negative consequences of unintentional disclosure being most heightened with young women's boyfriends or other sexual partners. Most of the young women had 
experienced unintentional disclosure, either before or during the study, often with damaging and adverse social consequences. For one participant, Rhoda, when her exboyfriend discovered her HIV status unbeknown to Rhoda after they had broken up, he told multiple friends about it, causing Rhoda significant worry and hurt:

I really hated it that these people found out about me without my choice. We are always learning in workshops that you have to think about how to disclose: who, when, where, why, how. Now I really hope I don't see these people ever, because of discrimination and all that. He made me feel like I was trash. (Rhoda, participant observation).

Rhoda's hurt about this experience was not only through the discrimination that she feared and experienced, but through her loss of control over the knowledge of her HIV status. Rhoda continued to describe the impact that this had on her, and her views on future disclosure:

I always used to be wary of telling boyfriends (that I was living with HIV), because I thought that they might bring it up if we ever fought. But now it has really made me lose my trust. If I have another boyfriend, I really won't tell him anything about my past and my status. I will wait until I really know him, and I am really sure before telling him. But if it does ever happen again, I now know I can deal with it. (Rhoda, participant observation)

Rhoda's HIV status was subsequently discovered later by fellow students in her boarding college, and the ensuing gossip forced her to move to another boarding college.

Where the choice around how and when was removed from the young women through unintentional disclosure, they sometimes experienced damaging and traumatic social consequences, exemplifying Goffman's "spoiled identity" (1963). This silence and secrets about their HIV status were therefore unstable and temporary, maintained until 
someone finds out. The fear of unintentional disclosure was linked to a fear of rejection, and being labelled as different from others. This rejection was experienced by some when unintentional disclosure did occur, leading to impacts on the young women's identity as viable girlfriends, friends or students, with disruptive and traumatic consequences. Links can be drawn with Abu-Lughod's understanding of female agency through Bedouin veiling (Abu-Lughod 1986). She described how, though choosing visual concealment by veiling, women negotiated hierarchical social relationships, enacting agency through a desire for conformity to a social ideal (Abu-Lughod 1986).

\section{Secrecy around ART}

All participants were taking ART during the study, and most had started ART several years before (Table 1). They recognised that being on ART helped them "look healthy" (Thandi, collage) and conceal their HIV status through their bodies, maintaining their identity as a "healthy" young person by reducing the risk of excessive weight loss. However, for many participants, ART was also the most potentially conspicuous everyday sign that they were living with HIV, and so they went to great lengths to conceal their medicines. For those who did not have a private space, either at home or in boarding college, keeping their ART in a secret space was described as "the biggest difficulty I have" (Mary, participant observation). The participants who stayed at boarding colleges had similar strategies to each other for storing their medicines in their shared dormitories with up to seven other students. For instance, Mary kept "a small supply of medicines inside a small medicine bag, in my backpack, which is kept on my bed, the top bunk" (Mary, participant observation). Her longer-term supply of ART was kept in a bottle at the bottom of her trunk, hidden under her clothes, where she felt it 
was least likely to be found by her roommates. But she described the challenges she faced transferring a new supply of pills into her small medicine bag in her shared dormitory without anyone seeing or asking questions.

Transporting ART from the health facility where the young women collected their new supply usually once every three months was seen as a potential risk of disclosure. In a peer education workshop observed at a health facility with one participant, common strategies of hiding or disguising ART once they had received it from the health facility were discussed. These included: throwing away the cardboard packaging of the ART before leaving the health facility; stuffing the bottles of ART with either paper or tissue to stop the noise of the pills rattling in the bottles; and emptying the ART into small plastic bags. The young women in the study similarly shared the strategies that they used for getting their ART ready to take at the same time each day without raising suspicion in the closing workshop. This included collecting the pills earlier than they needed to take them, then keeping them on their person (e.g. in their bras or in their pockets, wrapped in a tissue) until the designated time so as not to raise suspicions by going to their bags, or wherever they stored their ART, at the same time each day.

During the study period, many participants moved households to stay with different family members for periods of time from one night to several weeks or months. While in their main home, most participants had established somewhere private and safe to keep their ART. However, when they stayed with other relatives, many of whom did not know that they are living with HIV, hiding their ART became "really very difficult" (Sophie, participant observation). For some, their backpacks were the only private and safe space, as "everybody knows that you certainly should not go into other people's 
bags" (Sophie, participant observation). Some therefore carried their ART with them in their bags, wherever they went. For Rose, while staying with her brother, her ART were discovered by her sister-in-law, who looked through her clothes where the ART was hidden while Rose was out of the house. This led to an array of questions, leading Rose to feel that she was forced to invent a story, saying that she was given the medicines so that she could teach others about HIV and ART in support groups that she was facilitating. When a friend of Mary's discovered Mary's ART, the friend confronted Mary with a bottle of ART. Mary "felt scared that her secret was out", but then conversely "felt a great sense of relief" when her friend told her that she was also living with HIV, and that the bottle of ART she was holding was in fact her own (Mary, participant observation). This led to a close bond being developed between the two friends, who have since supported each other.

In other settings, non-HIV-identifying spaces for clinical and social HIV programs attempt to create a "normalising environment" (Fielden, et al. 2011). The young women in this study attempted to create such an environment in their home lives through concealment of their ART, thus encompassing use of space in their identity management. In both settings, we see the attempt to erase what Goffman refers to as the "stigma symbols" or visual reminders of HIV (1963:59). This is particularly relevant in contexts of limited private space, as seen here with shared bedrooms, communal storage space and collective belongings. This supports others who extend Goffman's focus on how the social order of stigma is maintained, to understand how the stigma norms may be challenged or resisted (Tyler 2018), while remaining cognisant of the structural and contextual boundaries that this can occur within 
(Kleinman and Hall-Clifford 2009). Here we see secrecy and concealment of ART as a resistance to HIV stigma, within the boundaries of limited privacy.

\section{Silence in language: Veiled language around HIV}

Verbally, participants used concealed language around HIV and ART, never once mentioning the word HIV during participant observations. Instead, words such as "dosed", "in my state" and "atopinga" (ie. 'topping up' with medicines) were used to refer to their being HIV positive, while others living with HIV were described as being "in my shoes", "she's like me" or "in my state". ART was rarely referred to as such, rather as "meds", and taking their ART was described as "drinking". In a card storm session in the closing workshop, the young women described more cryptic ways of talking about their ART with particular individuals who knew their HIV status. These included: "chocolate" or "toffee" (Thandi, with her mother); "cherry" (Mavis, with her boyfriend); "daily manna" (Mary, with her friend who is also living with HIV); "your beans", "therapy", or "snacks" (Rose, with her mother); and "manure" or "catalyst" (Sophie, who explained that she uses these words because the ART feeds your body and stimulates reactions in your body to keep you alive). They also sometimes referred to their ART as other medication, such as "panadol" (or paracetamol), to cover up what the medicines were really for. This contrasted to openness about other chronic diseases: one participant, Natasha, talked openly about her cousin's epilepsy medication, but then used veiled language about ART:

She takes her epilepsy medicine twice a day, and then that other one once a day at 20 hours. (Natasha, participant observation). 
One participant, Sophie also referred to ART as "chitupa" (translated as 'my identity card'), when speaking with her friend from church who was also living with HIV, implying that she viewed ART as a central part of her identity.

This veiled language was a form of HIV silence practiced by the young women almost subconsciously, using it with those who know their HIV status even in private spaces where there was no chance of being overhead. It became so normalised that as the researcher, I adopted the use of this veiled language when with participants and their families. As the researcher, my embroilment in the young women's silence and secrets raised complex ethical and practical implications, discussed in detail in a separate analysis (Mackworth-Young., et al. 2019). The practice of veiled language supports Squire's findings of how language can be used to evade the actualities of the condition, through the use of acronyms or coded language for HIV (Squire 2013). It can be seen to lead to HIV being rendered publicly silent, being pushed into the realm of private suffering (Squire 2013). However, among those living with HIV, this choice of veiled language can create a "secret fraternity of sickness" (Moore 1996:62), and can enable oblique and potentially supportive discussion of HIV issues between those with knowledge of each other's HIV status (Squire 2013). Here, the use of veiled language provided the young women with the ability to talk about HIV and ART, and their experiences of it, without being explicit, through the use of analogies and metaphors. This veiled language allowed the young women to speak without explicitly saying, to refer without naming, to infer without implicating, and by doing so, made the interaction of HIV in their relationships both safer and more ambiguous.

\section{Secrecy through stories: "I tell lies every single day"}


Beyond using veiled language, secrecy was practiced more explicitly in the young women's language through the use of stories, or in their words, "lies". Participants said they "tell lies every single day" (Mavis, workshop), including around their presence at the ART clinic, how their parents died, and what their ART was. When they went to the clinic, participants often had to invent stories to cover up where they were:

(My friend) kept on calling when I was at the clinic, asking where I was. So, I just had to say that I was in town doing a few things. But then she wanted to join me in town, so I had to lie again. (Mavis, participant observation).

Thandi, who was studying clinical medicine at college, described the challenges of excusing herself from classes when she went to the clinic, without being able to explain the reason why. Many of the young women spoke about telling multiple stories in order to cover up previous stories that they had told, and the challenges that ensued of having to try to remember who they had told what.

Since inventing cover-up stories was so commonplace for participants, they described adding another thing that they may have to conceal information about, namely this research study, as "not a big deal" (workshop). For them, this did not mean that being forced to invent stories did not impact them or their lives; rather it had become such a commonplace aspect of their everyday lives. During this research, participants frequently invented stories about the research and the researcher to hide their HIV status. For instance, Rhoda, when going to her house, told the researcher, If anyone asks, you should just tell them that we met at my work, at the printing shop. My Grandmother, she knows of course, but just if anyone else asks, it's best to tell them that. (Rhoda, participant observation). 
Other participants described me, the researcher, as "a friend" to people who asked how they knew each other. As such I, as the researcher, became embroiled in the "lies" that participants told to conceal their HIV status. This supports Madiega et al.'s findings of researchers being described as "church friends", "sisters-in-law" or "relatives" by participants and, while this was deemed necessary, it left some moral residue with the researchers (2013:25). Cognisant of the ethical importance of protecting participants' confidentiality, which was perceived to override the ethical need for transparency within research, such strategies may be essential to ensure active participation of young people living with HIV in such research.

The young women drew strength from employing responsive agency through telling such stories, keeping secrets and staying silent as a strategy to maintain relationships and their identities beyond HIV. As others have presented (Bond 2010; Hardon and Posel 2012), the young women in this study used secrecy as a social practice to control how others see them. The boundaries between what is revealed and what is withheld are fluid and shaped by personal choice (Hardon and Posel 2012). Here, these strategies largely enabled the young women to avoid unintentional disclosure of their HIV status. However, social and structural factors constrain these choices, sometimes very tightly indeed, and the choices can have challenging consequences.

\section{Fear and anxiety around secrecy: "I feel really bad lying"}

When asked in the closing workshop how they felt about having to practice secrecy to hide their HIV status, two participants wrote: 
We are both honestly okay with having to lie/ cover up about our status because people have different understandings about HIV so we lie to protect our social life and also to avoid stigmatistation. (Mavis and Mary, workshop).

However, in participant observations, these strategies were sometimes seen to create guilt around telling "lies" and anxiety that their lies might be discovered. Participants particularly worried that close friends, family and boyfriends would unintentionally find out about their HIV status:

The bad part is that I can't tell (my best friend). But I don't like it because there's no lie that can stay hidden forever. One day she is going to find out, the way she always borrows my clothes and goes through my stuff. I'm sure she's going to find out. (Mavis, participant observation).

This fear turned out to be well founded, as later this best friend did discover Mavis' status, leading to her telling other friends, speaking in negative terms about Mavis, and the end of their previously close friendship.

When participants did "lie" to hide their HIV status, they sometimes expressed guilt around telling "lies":

I feel really bad lying to that woman. I just didn't know what to say, so I made that up, but I should have just told the truth. (Rhoda, participant observation).

Rhoda brought the topic up again several hours later, saying

I still feel bad about lying to that woman. I always feel bad when I lie. It makes me feel so guilty inside. May God forgive me. (Rhoda, participant observation)

When the researcher then asked: "do you have to lie because of your status", Rhoda replied, "yes, a lot, all the time". During participant observation of a peer education session at an ART clinic that one participant was attending, a group of young people 
living with HIV discussed the benefits, the challenges and the Christian morals around telling "lies" to hide one's HIV status:

Yes, of course, lying is bad, and the Bible tells us not to do it, but sometimes lies can be your life-saver. (participant observation of peer education group with Rhoda).

While non-disclosure through the social practice of secrecy was, for some of the young women, an enactment of agency, the guilt and anxiety which these elicited demonstrates that the young women's agency was tightly "bounded" (Evans 2007) by the social context of persistent stigma. The regret about not being able to disclose to close friends, boyfriends and others shows how despite making choices around disclosure processes, and practicing strategies to manage their identity, their agency was bounded by social and structural factors. Here we see that silence and secrecy were practiced as a form of resistance, although only one that was attempting to navigate, rather than alter a social environment characterised by stigma.

When participants did not have to practice secrecy, because they had chosen to disclose their HIV status to certain people, they described the peace this provided:

It's so nice to be with someone who knows. I don't know how to describe it; it's just so peaceful. She just understands; I don't need to explain or tell stories. (Mavis, participant observation).

I felt like a weight had been lifted off my chest, I felt so much lighter (Rhoda, participant observation)

Mary, who had disclosed to four close friends, described the benefits of this disclosure:

This is the most important bit, having friends who support you and accept you for you who are. (Mary, participant observation).

Other participants emphasised the freedom they gained from disclosing to friends: 
I took my friend to the clinic to disclose my status to her: I knew she wouldn't believe it if I just told her. We've been close friends for years, we were at school together, but I just never felt like I could tell her before now. When she realised, she told me that she was also HIV-positive. I couldn't believe it. But we're now closer than ever, we've shared all our stories, and it's so nice that I can be completely free with her. (Sophie, participant observation).

This freedom, support and relief that the young women experienced with those they had chosen to disclose to, as well as with others living with HIV supports other evidence demonstrating the value of psycho-emotional support for young people living with HIV (Mupambireyi 2017; Mupambireyi, et al. 2014).

\section{Secrecy and silence beyond HIV}

The young women living with HIV went to great lengths to conceal their HIV status through secrecy and lies. However, Sophie's statement that "everybody knows that you certainly should not go through other people's bags" illustrates that everyone has things that they do not want to reveal. In the workshop with young people with unknown or negative HIV status, several of the participants agreed that they "don't like announcing things about ourselves" (Winnie, workshop). They said they would assess whom they could trust to share certain issues with. In particular, they would avoid talking to their parents about relationships, and would avoid telling friends some things to avoid judgement and envy: "I don't want to share things with friends because of jealousy" (Mwangala, workshop). One young woman declared that there were some particular major, and challenging, aspects of her experience and identity that she selects to keep silent about: 
"I share most things with everyone, but there are some secrets, some big secrets, that make me scared to even think about. There are some secrets that even make me cry when I think about them" (Tila, workshop).

Ill health was one issue that the young women in the workshop were clear that they would want to keep private, including, but not restricted to HIV:

"You would definitely hide your HIV status or any other disease or health status" (Brenda, workshop).

These young women with negative or unknown HIV status therefore were also acting within boundaries of choosing to keep certain identities and parts of their lives secret (Hardon and Posel 2012). Being young bounded their options more tightly, as did being female, with young women facing greater restrictions and social judgement on their choices and activities. These restrictions include where they can move, who they can interact with, and the social connotations between young women, HIV and unsanctioned sex (Mackworth-Young, et al. 2017). The young women with negative or unknown HIV status admitted that they thought the boundaries would be more restrictive for those living with HIV. We suggest that being middle income, gave these young women (those with positive, negative and unknown HIV statuses) more options, compared to lower-income young women, including greater access to safe spaces through support groups peer education networks and financial ability to pay transport costs, thereby widening the boundaries within which they enacted agency.

\section{Conclusions}


The young women living with HIV in the ethnographic study disclosed their HIV status on a need-to-know basis, choosing to keep it secret from others to protect themselves from potential stigma arising from disclosure that they deemed unnecessary. Through this, they drew strength from employing responsive agency by using secrecy and silence as strategies in response to social relationships to retain choice over who, how, where and when to disclose their HIV status. Where they were able to maintain the secret, they had the agency to shape and define what being HIV positive meant to them. However, the findings build on Evans' concept of "bounded agency" (Evans 2007) to show how the young women's agency to practice secrecy and silence was tightly bounded by the social context of persistent stigma. Despite the accompanying guilt and anxiety, for some, secrecy and silence were seen as necessary to avoid the potentially traumatic consequences of unintentional disclosure.

Our findings question the pejorative dimension of secrecy and silence which are often opposed to the cherished social values of truth and honesty (Stadler, et al. 2016), to argue instead that they can be used as active strategies to protect one's identity in a context of a stigmatised disease and limited private space. We demonstrate the potential constructive power of secrecy and silence to control the flow of information, to protect against stigma, and as strategies to manage identity. Secrecy and silence, especially through the use of veiled language, presented the young women with a level of ambiguity to navigate their lives with HIV, enabling a balance between people knowing and having the possibility of people not knowing. Maman et al. have shown that nondisclosure of HIV can be a marker of other problematic aspects of a relationship (Maman, et al. 2016). Indeed, Mavis' decision not to disclose to her friend and Rhoda's decision not to disclose her boyfriend, led to traumatic social consequences when each 
unintentionally found out their status. The young women's judgement to withhold their HIV status was thus a reflection of the quality of the relationship and the predicted outcome of HIV disclosure. Secrecy was used as both a conscious and an intuitive strategy, particularly in environments with restricted privacy and high mobility for this middle-income group, with several attending boarding college and sharing rooms with other students, as also identified by Mutwa et al. (Mutwa, et al. 2013). These accounts show how secrecy and silence can be used as constructive practices, as "resistance against exclusion" and to safeguard against moral judgement (Dongen and Fainzang 2002:150).

This adds to an increasing body of knowledge that aims to shift towards greater nuance within assumptions and practices around the disclosure process (Fielden, et al. 2011; Galano, et al. 2017; Hardon and Posel 2012). Unlike some other secrets, within the context of HIV, privacy about HIV becomes a secret that must be shared. Viewing the silence practiced by young people with regard to their HIV status as subversive (Hardon and Posel 2012) holds them to a higher threshold of transparency than we ask of others. In the context of Undetectable=Untransmittable $(\mathrm{U}=\mathrm{U})$ (The Lancet HIV 2017), and in view of evidence from South Africa showing that the disclosure of young people's HIV-positive status to sexual partners does not lead to safer sex (Toska, et al. 2015), assumptions that disclosure to sexual partners is universally constructive for young people living with HIV are questionable. This is particularly the case for this group of middle-income young women, who have access to high standards of care, including routine viral load testing, and so can regularly monitor their viral load. These prescriptive disclosure assumptions underlie international guidance on HIV that frequently emphasises the importance of disclosure, and reflects global narratives 
urging disclosure to sexual partners (World Health Organization 2013). In some settings, non-disclosure of HIV status is criminalised (Hurley 2018). Yet, for the young women in this study, disclosing to boyfriends was potentially the most damaging for their identity. This more nuanced approach interrogates global and local counselling guidelines that recommend disclosure, especially to all sexual partners. As Hardon and Posel argue, rather than "calls to normalise HIV/ AIDS through routine practices of disclosure... a culturally sensitive balance between truth-telling and silence may sometimes be more appropriate" (Hardon and Posel 2012:5).

Previous research has shown that young people manage a 'truth economy', choosing what information to share with healthcare providers (Bernays, et al. 2017). Where healthcare providers singularly encourage disclosure without due attention to possible harmful outcomes, there is a risk that this could lead to damaging the wider supportive relationship young people may have and could possibly lead to withholding other information and avoiding clinical spaces for support. Disclosure counselling should adapt to account for the importance of this agency and support young people with such strategies to manage their identities. Counsellors should therefore acknowledge and support settings and cases where it may be "neither morally appropriate nor tactically advantageous to disclose" (Hardon and Posel 2012:9).

The value of psycho-emotional support is demonstrated by the freedom, support and relief the young women experienced with those they had chosen to disclose to as well as with other young women living with HIV. Support groups with other young people living with HIV have been shown to provide a valuable safe space, where they receive social support and can feel "normal" through being "among others who are just like 
me" (Barker, et al. 2019; Mupambireyi, et al. 2014:110,106). They can provide a muchneeded space for young people living with HIV to be open, free from necessitated secrecy and fear and without worrying about the consequences, in contrast to the rest of their lives when they are bounded by the social context of persistent stigma. Support with the disclosure process can equip young women living with HIV with the skills to make decisions around who, when, where and why to disclose their HIV status, and strategies both for choices to disclose as well as not disclose (Evangeli, et al. 2018). With an overwhelming focus on treatment adherence in adolescent programs (Bernays, et al. 2017), this support and advice on disclosure is often overlooked, but strongly needed. Further, such support could alleviate some of the guilt and anxiety experienced by the young women living with HIV around the secrecy and silence that they practice. 


\section{References}

Abu-Lughod, L.

1986 Veiled Sentiments: Honor and poetry in a Bedouin society. Oakland, California: University of California Press.

Barker, D., et al.

2019 In-Clinic Adolescent Peer Group Support for Engagement in SubSaharan Africa: A Feasibility and Acceptability Trial. Journal of the International Association of Providers of AIDS Care $18: 2325958219835786$.

Bernays, S., et al.

2017 'Not Taking It Will Just Be Like A Sin': Young People Living With HIV And The Stigmatization Of Less-Than-Perfect Adherence To Antiretroviral Therapy. Med Anthropol.

Bond, $\mathrm{V}$.

2010 "It is not an easy decision on HIV, especially in Zambia": opting for silence, limited disclosure and implicit understanding to retain a wider identity. AIDS Care 22 Suppl 1:6-13.

Bourdieu, P.

1977 Outline of a Theory of Practice. Cambridge: Cambridge University Press.

Bury, M.

1982 Chronic illness as biographical disruption. Sociology of Health \& Illness 4(2):167-182.

Central Statistical Office, and . Ministry of Health 
2014 Zambia Demographic and Health Survey 2013-14. M.o. Health and Z.a.I. International.

Corbin, J., and A. Strauss

1987 Accompaniments of chronic illness changes in body, self, biography and biographical time. Research in the Sociology of Health Care 6:249-81.

Cusick, L., and T. Rhodes

1999 The Process of Disclosing Positive HIV Status: Findings from Qualitative Research. Culture, Health \& Sexuality 1(1):3-18.

Denison, J. A., et al.

2015 "The sky is the limit": adhering to antiretroviral therapy and HIV self-management from the perspectives of adolescents living with HIV and their adult caregivers. J Int AIDS Soc 18:19358.

Dongen, E., and S. Fainzang

2002 Lying, misery and illness: Towards a medical anthropology of the lie. Anthropol Med 9(2):85-95.

Evangeli, M., I. Lut, and A. Ely

2018 A longitudinal evaluation of an intensive residential intervention (camp) for 12-16 year olds living with HIV in the UK: evidence of psychological change maintained at six month follow-up. AIDS Care:1-5.

Evans, K.

2007 Concepts of bounded agency in education, work, and the personal lives of young adults. International Journal of Psychology 42(2):85-93.

Fenton, L.

2004 Preventing HIV/AIDS through poverty reduction: the only sustainable solution? Lancet 364(9440):1186-7. 
Fielden, S. J., G. E. Chapman, and S. Cadell

2011 Managing stigma in adolescent HIV: silence, secrets and sanctioned spaces. Culture Health \& Sexuality 13(3):267-81.

Freeman, E.

2017 Neither 'foolish' nor 'finished': identity control among older adults with HIV in rural Malawi. Sociol Health Illn 39(5):711-725.

Frye, V., et al.

2009 Managing identity impacts associated with disclosure of HIV status: a qualitative investigation. AIDS care 21(8):1071-1078.

Galano, E., et al.

2017 Costs and benefits of secrecy: the dilemma experienced by adolescents seropositive for HIV. AIDS Care 29(3):394-398.

Goffman, E.

1963 Stigma; notes on the management of spoiled identity: Englewood Cliffs, N.J. : Prentice-Hall.

Hardon, A., and D. Posel

2012 Secrecy as embodied practice: beyond the confessional imperative. Culture Health \& Sexuality 14 Suppl 1:S1-13.

Hurley, R.

2018 Criminalising HIV transmission is counterproductive and should stop, experts say. British Medical Journal 362.

Khanare, F.

2012 Schoolchildren affected by HIV in rural South Africa: schools as environments that enable or limit coping. Afr J AIDS Res 11(3):251-9.

Kleinman, A., and R. Hall-Clifford 
2009 Stigma: a social, cultural and moral process. J Epidemiol Community Health 63(6):418-9.

Link, B. G., and J. C. Phelan

2001 Conceptualizing Stigma. Annual Review of Sociology 27(1):363385.

Long, D., and K. Deane

2015 Wealthy and healthy? New evidence on the relationship between wealth and HIV vulnerability in Tanzania. Review of African Political Economy 42(145):376-393.

Mackworth-Young, C., et al.

2017 "My mother told me that I should not": A qualitative study exploring the restrictions placed on adolescent girls living with HIV in Zambia. Journal International AIDS Society 20:e25035.

Mackworth-Young., et al.

2019 Navigating 'ethics in practice': An ethnographic case study with young women living with HIV in Zambia. Global Public Health:1-14.

MacPherson, P., et al.

2012 Barriers and facilitators to linkage to ART in primary care: a qualitative study of patients and providers in Blantyre, Malawi. J Int AIDS Soc 15(2):18020.

Madiega, P. A., et al.

2013 'She's my sister-in-law, my visitor, my friend' -- challenges of staff identity in home follow-up in an HIV trial in Western Kenya. Developing World Bioethics. 13(1):21-9.

Maman, S., et al. 
2016 Diagnosis and Disclosure of HIV Status: Implications for Women's Risk of Physical Partner Violence in the Postpartum Period. J Acquir Immune Defic Syndr 72(5):546-51.

Mburu, G., et al.

2014 Adolescent HIV disclosure in Zambia: barriers, facilitators and outcomes. J Int AIDS Soc 17:18866.

Moore, 0 .

1996 PWA: Looking AIDS in the face. London: Picador.

Mupambireyi, Z.

2017 Peer networks and social support and its influence on young people's experience of growing up with HIV, University of London.

Mupambireyi, Z., et al.

2014 "I don't feel shy because I will be among others who are just like me...": The role of support groups for children perinatally infected with HIV in Zimbabwe. Children and Youth Services Review 45:106-113.

Mutwa, P. R., et al.

2013 Living Situation Affects Adherence to Combination Antiretroviral Therapy in HIV-Infected Adolescents in Rwanda: A Qualitative Study. PLOS ONE 8(4):e60073.

Nguyen, V-K.

2010 The Republic of Therapy: Triage and Sovereignty in West Africa's Time of AIDS. Durham and London: Duke University Press.

2013 Counselling against HIV in Africa: a genealogy of confessional technologies. Culture Health \& Sexuality 15 Suppl 4:S440-52. 
Nostlinger, C., et al.

2015 Factors influencing social self-disclosure among adolescents living with HIV in Eastern Africa. AIDS Care 27 Suppl 1:36-46.

Paxton, S.

2002 The paradox of public HIV disclosure. AIDS Care 14(4):559-67.

Pincock, K.

2017 'Fucking not kissing': Teenage girlhood and sexual agency in rural Tanzania, Bath.

Russell, S., and J. Seeley

2010 The transition to living with HIV as a chronic condition in rural Uganda: working to create order and control when on antiretroviral therapy. Soc Sci Med 70(3):375-382.

Seeley, J., et al.

2012 HIV and identity: the experience of AIDS support group members who unexpectedly tested HIV negative in Uganda. Sociol Health Illn $34(3): 330-44$

Seffren, V., et al.

2018 Association between coping strategies, social support, and depression and anxiety symptoms among rural Ugandan women living with HIV/AIDS. AIDS Care:1-8.

Simpson, A.

2009 Boys to Men in the Shadow of AIDS: Masculinities and HIV Risk in Zambia. New York, US: Palgrave Macmillan US.

Skovdal, M., and M. Daniel 
2012 Resilience through participation and coping-enabling social environments: the case of HIV-affected children in sub-Saharan Africa. Afr J AIDS Res 11(3):153-164.

Skovdal, M., and V. O. Ogutu

2013 Coping with hardship through friendship: the importance of peer social capital among children affected by HIV in Kenya. Afr J AIDS Res 11(3):241-250.

Squire, C.

2013 Living with HIV and ARVs: Three-letter lives. UK: Palgrave Macmillan UK.

Stadler, J., et al.

2016 Adherence and the Lie in a HIV Prevention Clinical Trial. Medical anthropology 35(6):503-516.

Stoebenau, K., et al.

2016 Revisiting the understanding of "transactional sex" in sub-Saharan Africa: A review and synthesis of the literature. Soc Sci Med 168:186-197.

The Lancet HIV

2017 U=U taking off in 2017. The Lancet HIV 4(11):e475.

Theron, L. C., and A. M. C. Theron

2010 A critical review of studies of South African youth resilience, 19902008. South African Journal of Science 106:1-8.

Toska, E., et al.

2015 Sex and secrecy: How HIV-status disclosure affects safe sex among HIV-positive adolescents. AIDS Care 27 Suppl 1:47-58.

Tyler, I. 
2018 Resituating Erving Goffman: From Stigma Power to Black Power. The Sociological Review 66(4):744-765.

World Health Organization

2013 HIV and adolescents: Guidance for HIV testing and counselling and care for adolescents living with HIV. WHO.

2017 Health for the World's Adolescents: A second chance in the second decade WHO. 